\title{
Seasonality in speleothems
}

lan J. Fairchild1', M. Bar-Matthews², P. M. Wynn ${ }^{3}$ and I. J. Orland ${ }^{4}$

\section{Seasonal signals are transmitted to speleothems via the quantity, chemistry and isotopic composition of dripping water in caves. Modern techniques allow seasonality to be interpreted through variations in trace elements, stable} isotopes, and organic fluorescence within annual layers.

Records from calcareous cave deposits (speleothems) can reveal large-scale variations in the climate system over long time periods (Bar-Matthews et al. 2003; Fairchild and Baker 2012). These records require the direct transmission of an atmospheric signal to the speleothem, and uranium-series dating to construct a precise and accurate age model (Cheng et al. 2009). As with other natural archives, ambiguities remain with the climatic interpretation of speleothem records. For example, the mean oxygen isotope composition of speleothems in monsoon-influenced areas has been interpreted as indicating the relative strength of summer versus winter monsoons (Wang et al. 2001). Hence, it is desirable to resolve and understand seasonal processes, particularly those related to rainfall (Johnson et al. 2006; Hu et al. 2008; Orland et al. 2009, 2012). However, how are seasonal signals captured in a cave?

\section{Cave climate and seasonality}

Seasonal changes are muted in cave interiors, which are archetypically isothermal, fetid and humid. Therefore, temperatures are usually close to the external annual mean. The difference in external and internal temperatures can lead to density-driven air circulation, which is typically enhanced in the winter, which is also the season of lower levels of $\mathrm{CO}_{2}$ in the cave atmosphere. This leads to more degassing of $\mathrm{CO}_{2}$ from dripwaters and causes speleothems to grow faster in winter than in summer (Wong et al. 2011). A common consequence of this seasonal bias in calcite precipitation is seasonal oscillation of ${ }^{13} \mathrm{C}, \mathrm{Mg}$ and $\mathrm{Sr}$ concentrations in speleothems (Fairchild et al. 2000; Frisia et al. 2011; Tremaine and Froelich 2013).

The flow-path of dripwater into the cave can also affect the preservation of seasonal signals in speleothems. Overlying karstic carbonate bedrock contains fractures that provide a rapid routing of water away from the surface, while networks of finer pores in the matrix only enable seepage flow. Fracture and pore flow are mixed in varying proportions in dripwaters. Therefore, the quantity and chemical composition of dripwater reflect the magnitude and pattern of rainfall or snowmelt and the pathways of its delivery to the karst system via the overlying soil.

A range of potential consequences arises from the drip-specific hydrological regime - thin laminae in speleothems contain chemical impurities from rainfall infiltration events whereas the dry season usually results in enrichments in trace elements (Baker et al. 2000; Fairchild et al. 2000; Fairchild and Treble 2009). When travel times of water are short, seasonal variations in the oxygen isotope composition of rainfall are transmitted to caves and speleothems, but sites fed purely by seepage flow may have seasonally invariant $\delta^{18} \mathrm{O}$ compositions. Crucially, these properties can vary between adjacent speleothems in the same cave because of local variations in hydrological properties of the host rock. Hence, for scientists wanting to study climate at high resolution, a cave with speleothems is like the "à la carte" menu to a food-allergy sufferer: careful selection of what item to choose is vital.

\section{Annual and sub-annual properties of speleothems}

Annual lamination has been established as a common feature of stalagmites under a variety of climatic conditions (Baker et al. 1993; Orland et al. 2009). One type of lamination consists of narrow bands enriched in soil-derived organic matter. These bands are made visible by fluorescence microscopy. The laminae are enriched in trace elements (Borsato et al. 2007), which travel in water and are bound to organic ligands in colloids (Fairchild and Baker 2012). Background transmission of seepage waters containing fine humic molecules with a particular trace element signature should be distinguished from pulses of coarse colloids, which require hydrologically active conditions for their trace element patterns to be recorded (Hartland et al. 2012). Figure 1 illustrates what is perhaps the highest number of precipitation events in a single year ever documented in speleothems (Wynn et al. 2014). In Obir Cave in the Austrian Alps, high levels of lead and zinc, derived from local bedrock, record infiltration from individual synoptic rainfall events. Sensitivity is higher in autumn when vegetation dieback facilitates leaching loss of humic substances and of associated metals from the soil (Borsato et al. 2007).

The time of year is independently documented by the sulfate content of the calcite (analyzed as sulfur; Fig. 1). More sulfate ions are incorporated at high $\mathrm{PCO}_{2}$ (cave air $\mathrm{CO}_{2}$ partial pressure; Frisia et al. 2005). In the Obir cave $\mathrm{PCO}_{2}$ is higher during summer when the external air is warmer (and hence air density is lower) than in the cave. Thus, each summer and winter can be identified as high- (green-colored)

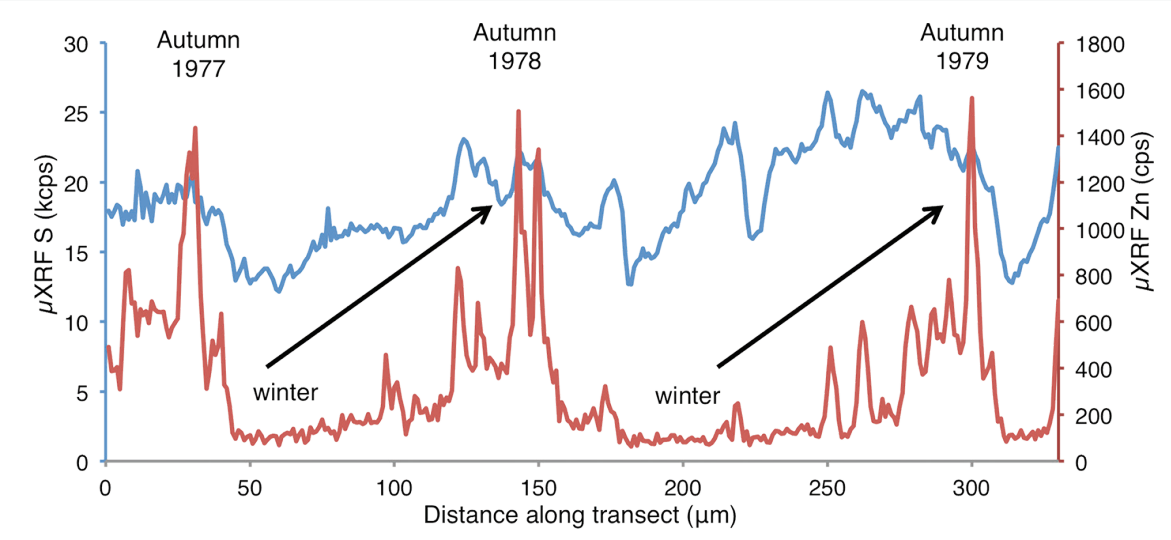

$\mathrm{Zn}$

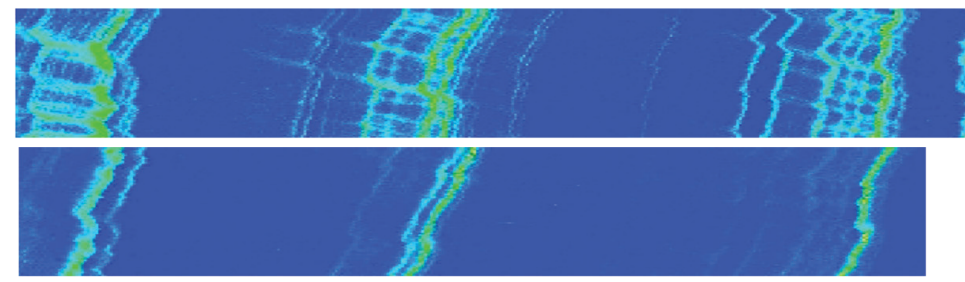

S

Figure 1: Three annual growth cycles in a speleothem from the Obir cave, Austrian Alps (Obi84) depicting relative concentrations of lead (Pb), zinc ( $\mathrm{Zn}$ ) and sulfur ( $\mathrm{S}$; known to be in the form of sulfate by absorption studies) mapped by micro-XRF synchrotron radiation. High-intensity banding ("greener") represents transport of organic-ligand-bound $\mathrm{Pb}$ and $\mathrm{Zn}$ during synoptic rainfall events. Highest intensity bands represent intense autumnal rainfall and loss of organic molecules and associated metals from the soil zone during times of vegetation dieback. Relative concentrations of $\mathrm{S}$ demonstrate independent verification of seasonality and timing of the autumnal flush of $\mathrm{Zn}$ and $\mathrm{Pb}$. Low winter $\mathrm{S}$ concentrations are a product of low cave chamber $\mathrm{PCO}_{2}$ and high carbonate to sulfate ratios during speleothem growth. From Wynn et al. (2014) with permission. 

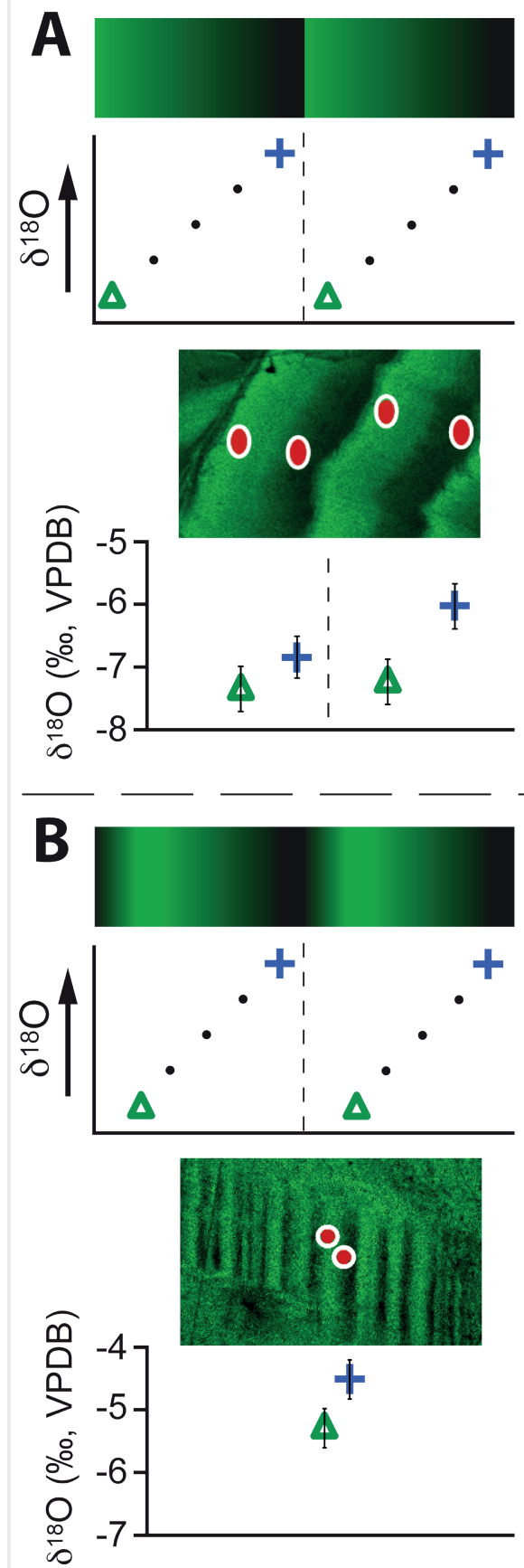

younger
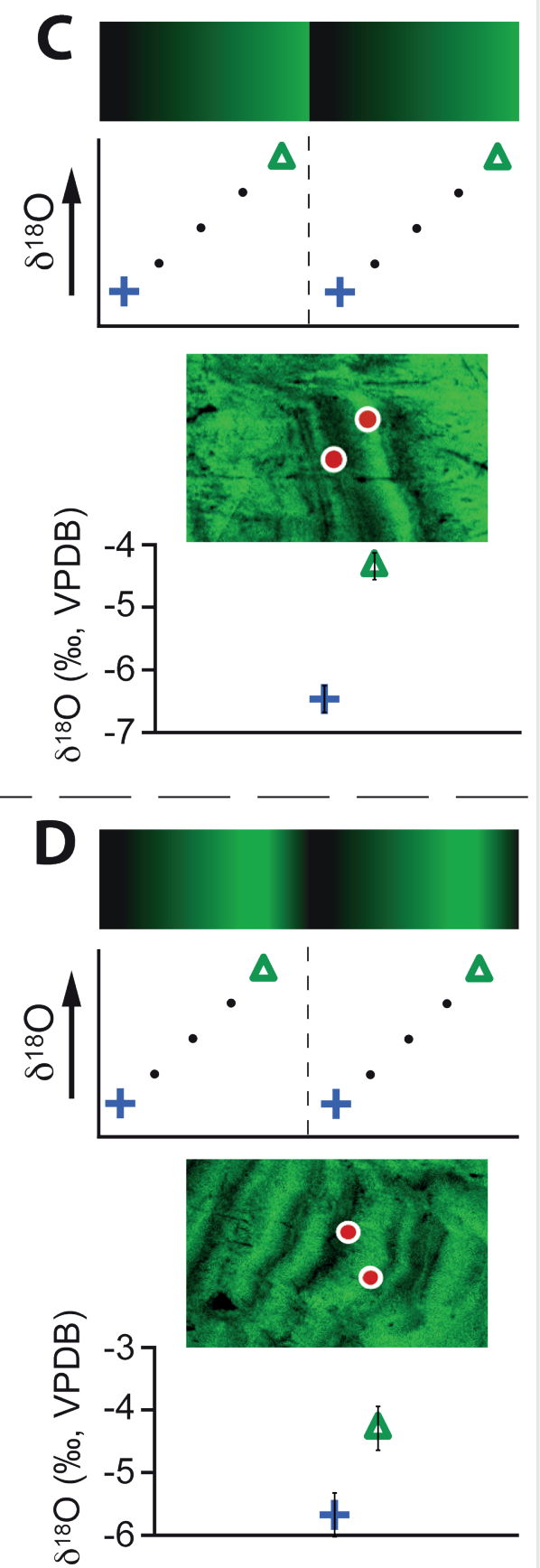

Figure 2: Examples of four patterns (A-D) of fluorescent banding and $\delta^{18} \mathrm{O}$ variability observed on annual growth bands in a stalactite from Soreq Cave (Israel) that grew from 34 to $4 \mathrm{ka}$. A schematic of each pattern is shown above an example from the speleothem. The spots analyzed for $\delta^{18} \mathrm{O}$ by ion microprobe are marked by red dots, $\sim 10 \mu \mathrm{m}$ in diameter, on the image of fluorescent banding acquired by confocal laser fluorescent microscopy. Green triangles and blue crosses mark $\delta^{18} \mathrm{O}$ values measured in areas of bright and dark fluorescence, respectively; each with $2 \sigma$ error bars. Note the range of $\delta^{18} \mathrm{O}$ analyses within single bands varies from 0 to $>2 \%$ (Figure adapted from Orland et al. 2012, which includes a climatic interpretation of these patterns).

and low-sulfate (blue-colored) zones in the speleothem, respectively (Fig. 1). Year-to-year variations in the seasonal sulfate oscillations can reveal the relative length of the warm and cold seasons.

A second type of annual lamination consists of couplets, alternately richer and poorer in fluid inclusions, varying in Mg-Sr chemistry and sometimes differing in mineralogy (Baker et al. 2008). Fundamentally, these laminae reflect an annual bimodality of water chemistry which usually can be correlated with either alternating warm and cold seasons that lead to varying $\mathrm{PCO}_{2}$ levels, or with summer drought, which leads to increases in $\mathrm{Mg}, \mathrm{Sr}$ and $\delta^{13} \mathrm{C}$ (Mattey et al. 2008; Boch et al. 2011; Orland et al. 2014).

The changing isotopic composition of water molecules is preserved in the $\delta^{18} \mathrm{O}$ signal of speleothem $\mathrm{CaCO}_{3}$. The $\delta^{18} \mathrm{O}$ variation within annual laminae can reflect the seasonal variability in composition of infiltrating water as well as the rainfall amount. However, evaporation in the soil zone and dampening of the seasonal signal by mixing processes during the infiltration can also influence the $\delta^{18} \mathrm{O}$ values (Ayalon et al. 1998).

A modern well-dated speleothem from Soreq Cave in Israel has revealed characteristic properties that can be used to trace the nature of seasonality and rainfall variability over time. Annual laminae are marked by fluorescent zones that are brighter in wetter years and are associated with $\delta^{18} \mathrm{O}$ variation. The range of $\delta^{18} \mathrm{O}$ correlates with the amount of rainfall in the corresponding year (Orland 2012). In older speleothems from Soreq Cave (Fig. 2), changes in the patterns of fluorescent banding and annual $\delta^{18} \mathrm{O}$ variability are also interpreted to reflect different seasonal climate regimes (Orland et al. 2012).

\section{Analytical frontiers}

The identification of sub-annual properties in speleothems depends on the presence of fast-growing, compact crystals (columnar fabrics are best, Frisia et al. 2000) with a growth surface that is either flat, or, if irregular, can be clearly imaged (Fig. 2). For trace elements, the $\mu \mathrm{m}$-scale resolution of $X$-ray fluorescence analysis by synchrotron radiation provides the highest resolution that can be obtained to date. SIMS (secondary ionization mass spectrometry) has a resolution of several microns and provides unique data on elements that are difficult to analyze by other means (Fairchild et al. 2001). Accurate and precise laser-ablation inductively coupled plasma mass spectrometry (LA-ICPMS) has $\sim 10 \mu \mathrm{m}$ resolution, which is sufficient to resolve seasonal properties for faster growing samples. For stable isotopes, faster-growing samples can be sub-sampled by micromilling with a resolution of $\sim 100 \mu \mathrm{m}$ and analyzed by mass spectrometry (Drysdale et al. 2012). Laser ablation offers a more rapid alternative for stable isotope analysis if care is taken to screen out artifacts (Spötl and Mattey 2006). The oxygen isotope SIMS analysis of Figure 2 was achieved with a spot size of $10 \mu \mathrm{m}$, resolving seasonal variations in bands as narrow as 20-30 $\mu \mathrm{m}$ (Orland et al. 2009, 2012).

\section{AFFILIATIONS}

'School of Geography, Earth and Environmental Sciences, University of Birmingham, UK

${ }^{2}$ Geological Survey of Israel, Jerusalem, Israel

${ }^{3}$ Lancaster Environment Centre, Lancaster University, UK ${ }^{4}$ Department of Earth Sciences, University of Minnesota, Minneapolis, USA

\section{CONTACT}

lan J. Fairchild: i.j.fairchild@bham.ac.uk

\section{SELECTED REFERENCES}

Full reference list under:

http://www.pages-igbp.org/products/newsletters/ ref2014_1.pdf

Fairchild IJ, Baker A (2012) Speleothem Science. From Process to Past Environments. Wiley-Blackwell, $450 \mathrm{pp}$

Mattey DM et al. (2008) Earth Planet Sci Lett 269: 80-95 Orland IJ et al. (2012) Geochim Cosmochim Acta 89: 240-255

Orland IJ et al. (2014) Chem Geol 363: 322-333

Wynn PM et al. (2014) Environ Chem 11: 28-36 